\title{
VARIAS OBRAS ATRIBUIBLES AL ESCULTOR SEVILLANO CRISTÓBAL RAMOS EN LA RIOJA
}

\author{
FERMÍN LABARGA ${ }^{1}$ \\ Universidad de Navarra
}

\begin{abstract}
Hasta ahora, la producción artística del escultor Cristóbal Ramos se localizaba en el entorno de Sevilla. Sin embargo, gracias a la labor de patronazgo ejercida por los emigrantes cameranos algunas piezas llegaron hasta La Rioja. Se presentan cuatro que pueden ser relacionadas con la producción del artista.

Palabras clave: escultura; Dolorosa; Calvario; Cristóbal Ramos; Sevilla; La Rioja
\end{abstract}

\section{SEVERAL WORKS THAT CAN BE ATTRIBUTED TO THE SEVILLIAN SCULPTOR CRISTÓBAL RAMOS IN LA RIOJA}

\begin{abstract}
Until now, the known works of the sculptor Cristobal Ramos were only to be found around Seville. However, as a result of the artistic patronage exercised by emigrants from Cameros, some of his works ended up in La Rioja. This paper presents four pieces that can be related to the artist's production.

Key words: sculpture; Our Lady of Sorrows; Calvary; Cristóbal Ramos; Seville; La Rioja.
\end{abstract}

Cómo citar este artículo / Citation: Labarga, Fermín (2019): "Varias obras atribuibles al escultor sevillano Cristóbal Ramos en La Rioja". En: Archivo Español de Arte vol. 92, núm. 368, Madrid, pp. 435-442. https://doi. org/10.3989/aearte.2019.28.

Cristóbal Ramos (Sevilla 1725-1799)2 , Teniente de Escultura de la Real Academia de las Tres Nobles Artes, es uno de los mejores exponentes de la escuela sevillana de escultura e imaginería de la segunda mitad del siglo XVIII. En su producción se refleja el tránsito desde el tardobarroco, a través del rococó, hacia el incipiente academicismo neoclásico. Hasta el presente, la totalidad de la producción artística de este escultor e imaginero se localizaba en el entorno más cercano a la capital hispalense, donde tenía su taller, repartiéndose por la provincia y las limítrofes de Cádiz, Córdoba y Huelva ${ }^{3}$. Sin embargo, gracias a la labor de patronazgo ejercido por los emigrantes cameranos asentados en Sevilla algunas piezas llegaron hasta La Rioja. Presentamos varias que pueden serle atribuidas atendiendo tanto a la documentación conservada como a sus características tipológicas y morfológicas.

\footnotetext{
1 flabarga@unav.es / ORCID iD: http://orcid.org/0000-0002-8088-4269.

2 La única monografía publicada, hasta la fecha, sobre este autor es la de Montesinos, 1986. Una bibliografía actualizada puede verse en Moreno Arana, 2017: 819-826 y en Roda Peña, 2018.

${ }_{3}^{3}$ Roda Peña, 2014: 93-94. Recientemente se le han atribuido otras piezas fuera de este ámbito territorial: Martínez Lara — de la Torre, 2017.
} 


\section{La Virgen del Mayor Dolor en Ajamil}

La emigración riojana hasta Andalucía ha sido puesta de relieve en los últimos años, destacando figuras notables de gran importancia en el sector industrial y del comercio, fundamentalmente a partir de la segunda mitad del siglo XVIII y durante toda la centuria decimonónica. La presencia de riojanos en Sevilla cristalizó también en la erección de una hermandad en honor de la Virgen de Valvanera. Otro tanto ocurrió en Cádiz, hasta donde se desplazaron muchos de ellos a raíz del traslado de la Casa de Contratación ${ }^{4}$.

Normalmente, los emigrantes que lograron hacer fortuna quisieron también ser agradecidos con sus localidades de origen, para lo cual fundaron instituciones benéficas y académicas. De igual forma, contribuyeron al ornato de los templos parroquiales donde habían recibido las aguas bautismales. Así, en las iglesias riojanas, especialmente de las sierras, se localiza un interesante conjunto de piezas foráneas, tanto de pintura como de escultura y orfebrería, procedentes de la América colonial ${ }^{5}$ y de talleres de la Corte $^{6}$, al igual que de Andalucía, si bien todavía no se ha realizado un inventario de estas últimas.

Precisamente este fue el cauce por el cual llegó hasta la pequeña localidad de Ajamil de Cameros una imagen de la Virgen, bajo la advocación del Mayor Dolor, que atribuimos sin posibilidad de error, tanto por su datación (hacia 1776-1777) como por sus características morfológicas, al escultor Cristóbal Ramos.

Por medio de una carta, fechada en Sevilla el 19 de abril de 1778, el comerciante Josef Francisco de Llera Yñíguez, natural de "Axamil", manifestaba al cabildo eclesiástico de la iglesia parroquial de la Asunción de dicha localidad, que el 22 de febrero anterior había remitido "con el Arriero Fran.co Calleja y Compañeros, [...] para esa Yglesia, una Ymagen de la Ssma. Virgen María N. S. $\mathrm{r}^{\mathrm{a}}$ (su Adbocación) del maior dolor, que e savido aver llegado sin lesión, cuia noticia me a sido de mucho gusto, y la aguardava para escribir a V. S. dandole parte de mi yntención y voluntad sobre el destino de dicha S. Ymagen"7.

La voluntad del donante no era otra que "darla por donación a esa N. Yglesia Parroquial de Axamil; a cuia dadiva me estimula el zelo de la Sagrada Deboción a la Ssma Virgen, y el deseo de que se aumente y extienda, con utilidad y aprobechamiento espiritual de todos los individuos de ese mi estimado Pueblo, a quien amo íntima y tiernamente en el Señor". Corta "fineza" que pretendía quedara como "insinuación de mi Memoria" y "testimonio del buen afecto que profeso a esa mi querida Patria".

Por último, señalaba que todavía no le había "sido posible recoger los Memoriales, concesiones de yndulgencias, que e solicitado, y quedo en el cuidado de dirigirlos a V. S. lo antes que pueda". Se despedía, rogando a los señores del Cabildo "mui encarecidamente que en las Sagradas Funciones de N. SS. Madre, me tenga[n] presente en sus oraciones y sacrificios, y aga[n] recuerdo al Pueblo para que me encomiende a Dios"s.

Josef Francisco de Llera Yñíguez había nacido en Ajamil el 24 de febrero de 1749. Era hijo de Manuel de Llera (o Illera), labrador de oficio, aunque perteneciente al estado noble, y de Josefa Yñíguez, oriunda de Soto de Cameros. Como tantos otros, el deseo de hacer fortuna (algo bastante difícil, por no decir imposible, en la sierra de Cameros) le llevó a emigrar, partiendo hacia Sevilla, donde se asentó y prosperó como comerciante.

A tenor de la carta más arriba citada, puede suponerse que todavía en 1778 permanecía en la capital hispalense, pero lo cierto es que poco después tenía su asiento ya en Cádiz. En 1782 in-

\footnotetext{
${ }^{4}$ Labarga, 2006: 175-225.

5 Cruz / Sánchez / Roldán, 1992.

6 Moya, 1988: 157-169. También pueden verse Ramírez, 1993 y Moya, 2005.

7 La imagen se colocó en el retablo del testero de la nave del Evangelio en un retablo rococó que parece construido ex profeso. La primera noticia que aparece corresponde a las cuentas del año 1781, cuando se gastaron "ocho rrs q costó un atril $\mathrm{p}^{\mathrm{a}} \mathrm{N}^{\mathrm{a}} \mathrm{S}$ del mayor dolor" según se anotó en el Libro de fábrica de la Parroquia de Ajamil (1752-1858), Archivo Histórico Diocesano de Logroño (AHDL), f. 98v.

${ }^{8}$ Libro de fábrica de la Parroquia de Ajamil (1752-1858), (AHDL), s.f.
} 


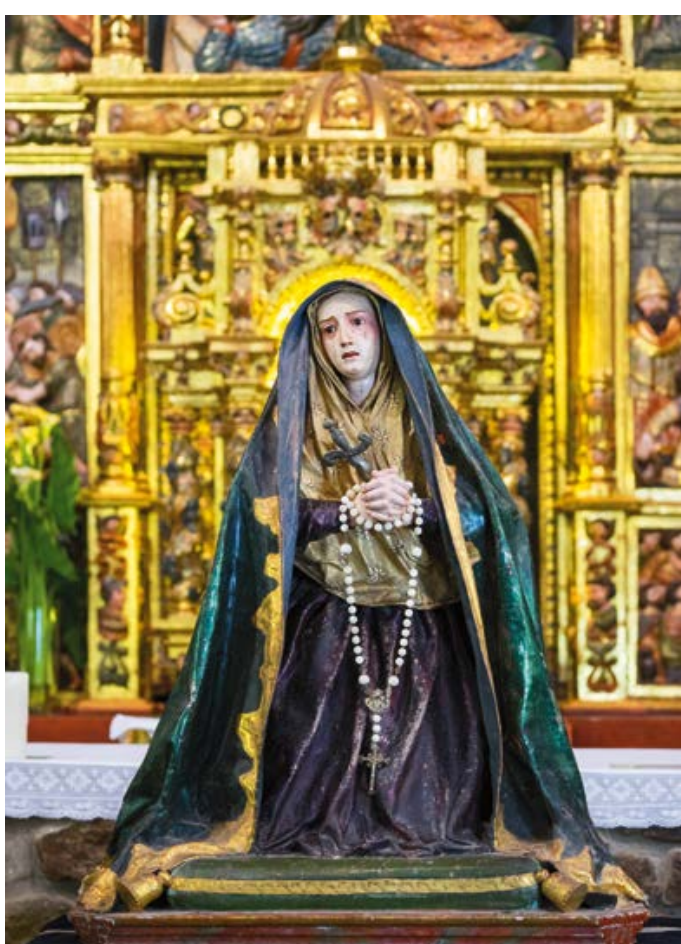

Fig. 1. Virgen del Mayor Dolor. Iglesia parroquial de Ajamil (La Rioja) Autor: Jaime Ocón Paillao. gresaba en la cofradía del Santísimo Cristo de la Humildad y Paciencia, conformada principalmente por los oriundos del País Vasco y Navarra9 ${ }^{9}$ En 1786 se matriculaba en el Consulado de comerciantes junto con su hermano Manuel Antonio ${ }^{10}$. El éxito en los negocios le permitió ingresar en el selecto y pujante mundo de la burguesía comercial gaditana, de la que también formaban parte otros muchos riojanos como Sebastián Martínez (de Treguajantes), los hermanos Ágreda (de San Román) o la dinastía de los Sáenz de Santa María, oriundos de Viguera. Como miembro del Solar de Valdeosera, fue su alcalde mayor (aun residiendo en Cádiz) en el bienio 1790-1791. Con su hermano Manuel formó una compañía para el comercio con América, cuya sede estaba en la calle de Murguía, $\mathrm{n}^{\circ} 149^{11}$.

La labor de promoción de su localidad natal se concretó en el caso de Josef Francisco de Llera, no solo en el envío de la imagen de la Virgen del Mayor Dolor para la iglesia parroquial, sino también en la fundación de las escuelas públicas de la localidad (una para niños y otra para niñas) en 1799 junto con Domingo Martínez García, miembro del Consejo de Hacienda durante el reinado de Carlos IV. Dota-

ron la fundación con los réditos "de un crecido capital que impusieron sobre la renta de tabacos", con los que se proveía a "la manutención del maestro, gastos de escuela y premios a los niños sobresalientes por su aplicación ó aprovechamiento"12.

Aunque la carta no indica la autoría de la imagen, lo cierto es que la Virgen del Mayor Dolor responde plenamente al estilo de Cristóbal Ramos, verdadero experto en la confección de este tipo de imágenes en las que destaca, junto con la belleza formal del rostro, la maestría en el uso de las telas encoladas y el extraordinario dominio del modelado en barro y en pasta de madera.

La imagen de la Virgen (fig. 1), de rodillas sobre un cojín de color verde con borlones dorados y una tira dorada que imita pasamanería, tiene unas dimensiones de 96 × 86 × $52 \mathrm{cms}$, tamaño inferior al natural, al igual que otras tantas piezas de Ramos. Presenta un minucioso acabado, tanto en los detalles del rostro, como en la indumentaria, muy rica tanto por el efecto del plegado de los paños como por la policromía, que imita las telas brocadas por medio de la técnica del cincelado (típica de la policromía rococó) tanto en la toca que envuelve el rostro (estofada con motivos florales) como en la suntuosa y elegante cenefa dorada del manto. Se advierte una policromía levemente metalizada, más evidente en el manto liso de color azul que en la túnica grana o púrpura, que contribuye igualmente a dotar de magnificencia a esta pieza. Dicho efecto metálico se debe al procedimiento utilizado, la corladura ${ }^{13}$.

\footnotetext{
${ }^{9}$ Garmendia, 1989: 197.

10 Ruiz, 1988: 178.

11 Guia de Cadiz para el año de 1811: Comprehende todas las oficinas respectivas a los ramos de Real Hacienda de esta provincia maritima, gobierno superior de esta plaza, su estado eclesiastico, el militar y el comercial de la misma, en la Imprenta de D. Josef Niel, Cádiz 1811, 98.

12 Madoz, 1845: 177.

13 Según http://tesauros.mecd.es/tesauros/tecnicas/1003820.html consiste en un "barnizado de láminas metálicas y panes de oro y plata con corla, un barniz de resinas y esencias generalmente coloreado, para modificar su superficie
} 


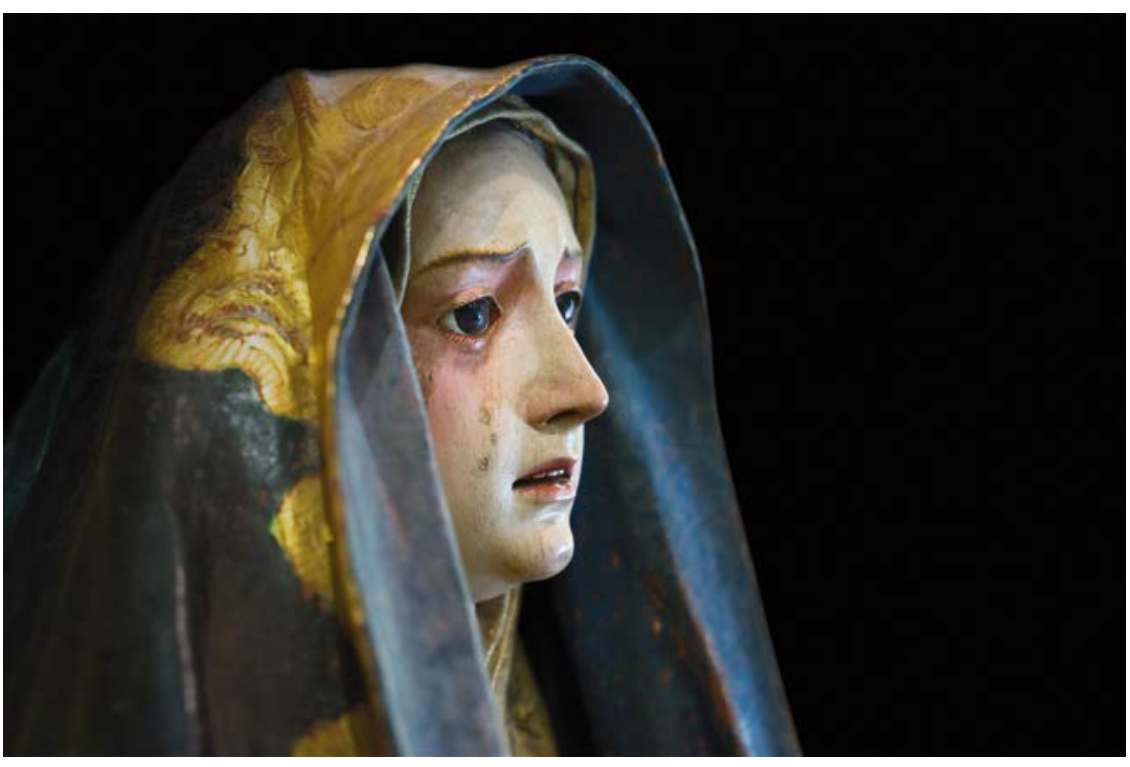

Fig. 2. Detalle del rostro de la Virgen del Mayor Dolor. Iglesia parroquial de Ajamil (La Rioja). Autor: Jaime Ocón Paillao.

Como suele ser habitual en este escultor, la cabeza está realizada en barro. El rostro (fig. 2), de gran belleza formal, muestra a la Virgen con un rictus de dolor, al que contribuyen poderosamente las cejas finas y onduladas, y la policromía de las mejillas, sonrosadas por efecto de la congoja y el llanto, quedando restos de lágrimas de cristal, que han desaparecido. Rasgo estilístico común con las imágenes de la Virgen de Ramos es igualmente la nariz recta y la boca pequeña y entreabierta, que permite ver los dientes superiores finamente modelados, así como el hoyuelo en la barbilla. Ligeramente vuelta hacia la izquierda, su mirada permanece levemente elevada, quedando los ojos enmarcados por finas pestañas pintadas sobre unos párpados inferiores algo abultados. Respecto a las manos, cabe señalar que aparecen entrelazadas a la altura del pecho, en la típica actitud de oración intensa y concentrada. El puñal de metal, no así la corona, parece ser el original y resulta casi idéntico a los que lucen otras imágenes de Ramos, como la de la Escuela de Cristo de Sevilla, llamada Consolatrix Afflictorum (a la que nos referiremos más abajo) y la Dolorosa del retablo del Santo Cristo de la capilla del Palacio de San Telmo de Sevi1la, con las que guarda una enorme similitud.

Se trata de una pieza de grandísima calidad, fechable en torno a 1776-1777, con unas características tipológicas y morfológicas tan próximas a otras imágenes de la Dolorosa de Cristóbal Ramos que no dudamos a la hora de atribuírsela. Necesita una limpieza general y la restauración de amplias zonas de las telas encoladas de las vestiduras, en algunas de las cuales puede verse la arpillera que está en el fondo.

Si bien no consta en el Libro de Fábrica que el retablo colateral de la nave del Evangelio fuera construido expresamente para colocar esta imagen, lo cierto es que encaja a la perfección en dicha máquina, de factura rococó, en la que destacan los espejuelos del camarín.

\section{Hasta Soto en Cameros por medio de la Santa Escuela de Cristo}

De Ajamil a Soto en Cameros solo hay 17 kilómetros. Soto fue el centro comarcal más importante de la zona y su conjunto urbano conserva todavía hoy un porte elegante, al que contribuyeron

(color, brillo, aspecto metalizado, etc.). En láminas de plata y estaño es muy frecuente la presencia de corlas amarillentas para imitar los panes de oro en el dorado. Las corlas se aplicaban en capas muy finas, a modo de veladura, para aprovechar la reflectividad del fondo metálico". 
de manera decisiva los emigrantes de la localidad, destacando entre todos los hermanos Manuel y Juan Antonio Jiménez Pérez, que dotaron el Hospital de San José, y Juan Esteban de Elías, fundador de las Escuelas. De Soto fue también oriundo el escultor de Cámara de la reina Isabel II, Francisco Elías Vallejo, del que se conservan varias imágenes en la iglesia parroquial de San Esteban.

En la sacristía de dicho templo, verdaderamente monumental, se conservan tres piezas, de las que al menos dos también pueden ser atribuidas con fundamento al escultor Cristóbal Ramos. Se trata de un Calvario, compuesto por un Crucificado y la Virgen a los pies, y de una imagen de la Dolorosa (cuyas características formales difieren, sin embargo, notablemente de la producción hasta ahora conocida del artista sevillano).

Está documentada la llegada del Calvario desde Sevilla, enviado por don Francisco Xavier Pablo en 1815. Con toda probabilidad se trata de las piezas que la segunda Santa Escuela de Cristo $^{14}$ erigida en la capital hispalense, con el título de la Natividad, donó a su secretario, Juan Josef Pablo Fernández, el 10 de diciembre de 1801. La donación se realizó una vez que éste regaló a la Escuela "una urna de caoba con una imagen de [la Virgen de los] Dolores del tamaño natural, con corona y cuchillo de plata sobredorada, que su costo ascendió a seis mil y setecientos reales, para adorno de la Sala de Juntas en el nuevo edificio del Oratorio"15. Esta imagen, a la que se le dio la advocación de Consolatrix afflictorum, había sido encargada al escultor Cristóbal Ramos, con quien Juan Josef Pablo debía mantener sólidas relaciones comerciales. Al mismo escultor, y probablemente también a través del propio Juan Josef Pablo, se le hizo el encargo de la imagen de la Virgen del altar mayor del Oratorio, a la que "se le puso la advocación de Mater Misericordi[a]e"16. Respecto de la cual señala la Historia de la fundación, establecimiento y progreso de la Escuela de Cristo, N. S. M', [del título de la Natividad], redactada por don Buenaventura Merino y Rioja ${ }^{17}$ :

"Era difícil hallar autor de tanta habilidad que llenase nros deseos, pero el que tenía mejor aceptación era don Josef Ramos (sic), hombre acreditado en trabajar en barro y en pasta. A éste, pues, se le encargó por un hermano hiciese una efigie dolorosa: la cabeza de barro, las manos de pasta y lo restante del cuerpo de madera y lienzo. En efecto, aunque no del todo, pero sí en lo principal salió de mucho mérito. El hermano encargado la custodió en su casa, sin darle la encarnación ni color en el ropaje. Mas luego que llegó el tiempo de concluirla, se excitó la questión sobre el color que debía tener así la túnica como el manto. Se consultaron a sujetos inteligentes $\mathrm{y}$ unos fueron de parecer que túnica y manto fuesen negros, otros túnica morada y manto negro, y otros finalmente, atendiendo a los colores que usaban los orientales, correspondía que la túnica fuese grana y el manto azul turquí, cuyo dictamen se adoptó, por las razones de la disertación" [que aportó don Ignacio de Valencia y Espinosa de los Monteros, capellán de la S. I. Catedral].

Huvo sujeto que se ofreció a costear la túnica y el manto de terciopelo de seda, mas atendiendo a la demejora que con el tiempo podía experimentar y al costo que tendría que hacer la Escuela para hacer otro igual vestido, no se admitió la oferta"18.

En efecto, la Junta de Ancianos de la Santa Escuela acordó "donar y ceder a dho nro hermano secretario el Cruzifixo con su peana y dosel, y la Señora de Dolores que actualmente sirve en

\footnotetext{
${ }^{14}$ Labarga, 2013: 315-317. Sobre la Escuela de la Natividad erigida en Sevilla y el cap. XI con datos sobre la construcción del oratorio, del retablo y de las imágenes.

15 Labarga, 2013: 719.

16 [Merino y Rioja, Buenaventura], Historia de la fundación, establecimiento y progreso de la Escuela de Cristo, N. S. $M^{o}$, [del título de la Natividad], [Sevilla 1814], Fundación Universitaria Española, Archivo del Instituto Orgánico de las Santas Escuelas de Cristo, Madrid (FUE /AIOSEC), f. 62.

17 Obediencia en repetidas ocasiones de la Santa Escuela, fue junto con el secretario Josef Pablo Pérez, el verdadero motor del esplendor artístico que desplegó dicha institución desde sus mismos inicios. Nacido en 1762 y natural de Redecilla del Camino, provincia de Burgos y obispado de Calahorra y La Calzada, era hijo de Francisco Merino y Ana Rioja. En 1791 presentaba las Informaciones de legitimidad y limpieza de sangre para la obtención del grado de Licenciado en Teología en la Universidad de Sevilla. Posteriormente obtuvo también el grado de Doctor en Sagrada Teología. Fue nombrado examinador sinodal del Arzobispado de Sevilla.

18 [Merino y Rioja], [1814]: ff. 45 y v. Mientras no se presenten mejores pruebas documentales en contrario, puede despejarse toda duda sobre la atribución de esta imagen.
} 
la sala de exercicios, por la veneración que el dho hermano tiene a estas Santa Ymágenes, y no tener la Escuela donde poder colocarlas"19.

Juan Josef Pablo Fernández nació en Soto el 10 de marzo de 1754, a las doce del mediodía, y fue bautizado el día 15. Era hijo legítimo de Xabier Pablo y de María Fernández ${ }^{20}$, matrimonio del que había nacido en 1751 Francisco Xavier ${ }^{21}$ y nacería en 1757 una niña, de nombre María ${ }^{22}$. Probablemente de la mano de algún pariente o conocido se trasladó a Sevilla, donde se dedicó al comercio. En 1793 se declaraba soltero y "mercader con tienda abierta de géneros de seda y joyería"23.

En ese mismo año se erigía la segunda Escuela de Cristo de Sevilla, la de la Anunciación, en la capilla de los Portugueses del convento Casa Grande de San Francisco, siendo su fundador Juan Josef Pablo, según reconoce Buenaventura Merino Rioja al redactar la historia de la institución. Como Secretario electo (y perpetuo en la práctica, a pesar de lo que señalaban las constituciones) fue el encargado de la redacción de las actas, en donde puede apreciarse la elegancia de su caligrafía. Por desavenencias con la cofradía de los Portugueses, en 1794 la Escuela se trasladaba al convento de los RR. PP. Clérigos Menores, iniciando posteriormente la construcción de un oratorio propio anejo a su templo (actualmente la iglesia parroquial de la Santa Cruz). En las obras jugó un papel muy destacado el secretario, al quedar al frente de su financiación y administración, según se puede comprobar en las listas de gastos presentadas ${ }^{24}$.

No cabe la menor duda de que Juan Josef Pablo Fernández fue el alma mater de la Santa Escuela y a él se deben en buena parte la disposición ornamental del nuevo oratorio y sus retablos. Parece cierto que mantenía una sólida relación comercial con Cristóbal Ramos, consolidada con el paso del tiempo. En 1793, recién fundada la Escuela, Juan Josef Pablo había hecho donación de un Nacimiento, compuesto por "el Niño Dios con sus potencias de plata, y cuna de madera adornada con su camita, María Santíssima con su corona de plata, San Josef con su diadema y vara de plata, el buey y la mula, con su hurna de christales y cinco ángeles, con obligación que dho Fernández a de tener en su poder y cuidar del Nacimiento hasta los días que lo necesite la Escuela" ${ }^{25}$. Su autor no era otro que Cristóbal Ramos. Hay que rectificar, por tanto, la datación ofrecida con anterioridad, que lo situaba en el año 1798 , adelantándola al menos un lustro ${ }^{26}$.

Tras el fallecimiento de don Juan Josef, su hermano Francisco Xavier, también perteneciente a la Escuela de Cristo e igualmente residente en Sevilla, quedó encargado de ejecutar el testamento. De acuerdo con lo establecido en dicho documento notarial, en 1815 remitió para la parroquia de Soto una cantidad de tres mil reales ${ }^{27}$ y diversas pertenencias de su difunto hermano ${ }^{28}$, entre ellas el Calvario procedente de la Santa Escuela de Cristo.

La cruz (fig. 3) (con una altura total de $150 \mathrm{cms}$, siendo el ancho de sus brazos de $85 \mathrm{cms}$ ) se inserta en un monte Calvario, en el que igualmente se acomoda la imagen de la Virgen. La

19 Libro I de Acuerdos de la Santa Escuela de Christo, del título de la Natividad, de la ciudad de Sevilla, Archivo de la Santa Escuela de Cristo de Sevilla, Sevilla (ASECS), f. 247 (10/12/1801).

${ }^{20}$ Libro $6^{\circ}$ de Bautizados de la Parroquia de Soto en Cameros (1747-1786), AHDL, ff. 127v-128. Abuelos paternos: Xabier Pablo y María Morales Cabezón. Maternos: Joseph Fernández González y María Vallexo. Padrino Joseph de Ariza Benito.

${ }^{21}$ Libro $6^{\circ}$ de Bautizados de la Parroquia de Soto en Cameros (1747-1786), AHDL, f. 77v.

${ }^{22}$ Libro $6^{\circ}$ de Bautizados de la Parroquia de Soto en Cameros (1747-1786), AHDL, f. 190v.

23 [Merino y Rioja], [1814]: f. 1.

${ }^{24}$ Libro I de Acuerdos de la Santa Escuela de Christo, del título de la Natividad, de la ciudad de Sevilla, ASECS, ff. $19,67,71,73,80$ y 85 .

${ }^{25}$ Libro I de Acuerdos de la Santa Escuela de Christo, del título de la Natividad, de la ciudad de Sevilla, ASECS, f. 35 .

26 Montesinos, 1986: 36

27 Libro de Fábrica de la Parroquia de Soto en Cameros (1740-1827), AHDL, f. 328: "Por un legado que yzo Dn Francisco Xavier Pablo, vecino de Sebilla y natural de esta villa... 3.000"; f. 329: "f. 329: "Por autorizar el recibo para cobrar el legado de Dn Francisco Xabier Pablo tres reales".

${ }^{28}$ Libro de Fábrica de la Parroquia de Soto en Cameros (1740-1827), AHDL, f. 329v.: "Por gastos de la conducción del resto del legado de Dn Francisco Xavier Pablo según cuenta de Dn Tomás Ybañez”, 8 rs y 9 mrs”. 


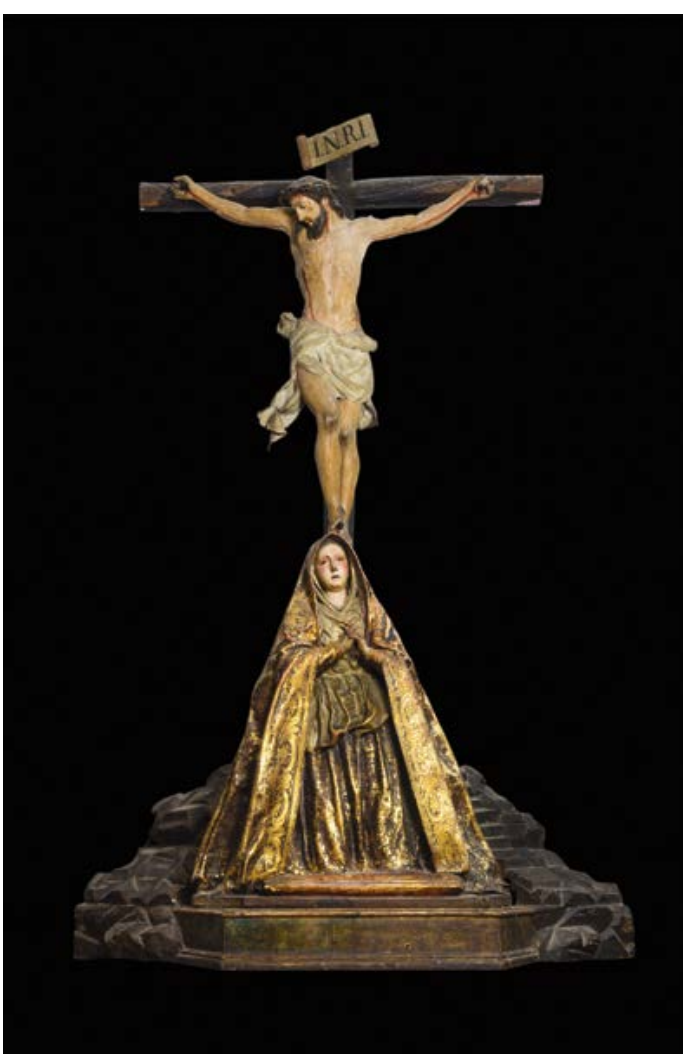

Fig. 3. Calvario. Sacristía. Iglesia parroquial de Soto en Cameros (La Rioja). Autor: Jaime Ocón Paillao.

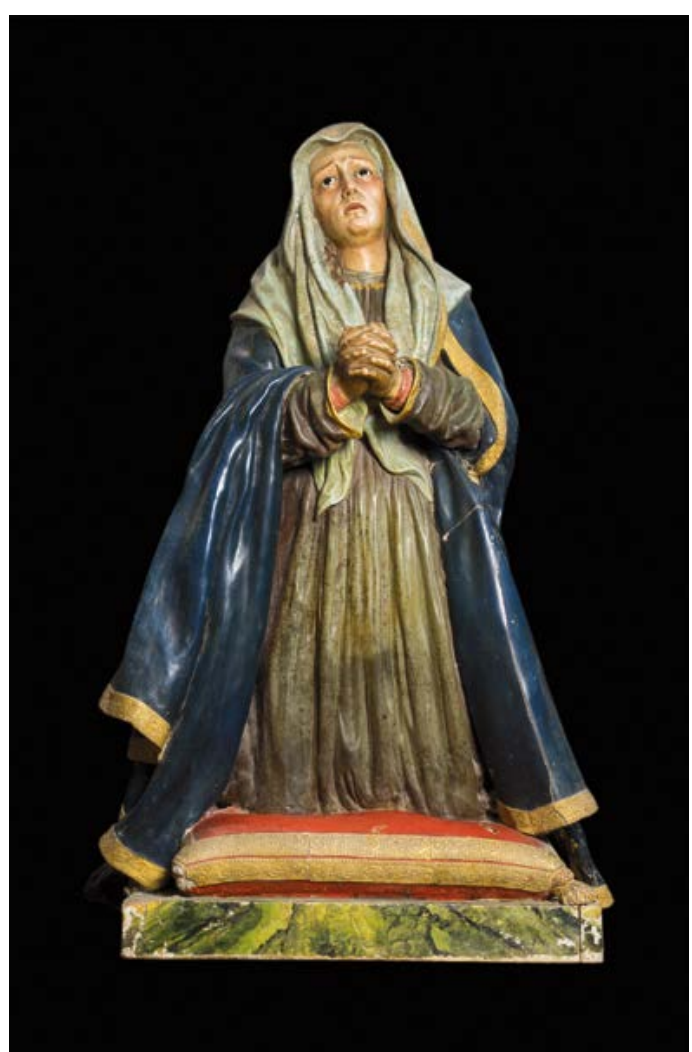

Fig. 4. Imagen de la Virgen. Sacristía. Iglesia parroquial de Soto en Cameros (La Rioja). Autor: Jaime Ocón Paillao.

imagen del Cristo, de papelón, que mide $78 \mathrm{cms}$ de alto y $67 \mathrm{cms}$ de envergadura de los brazos, guarda bastante semejanza con el del monasterio de Santa Paula de Sevilla, atribuido también a Cristóbal Ramos. La Virgen, con unas dimensiones de 65 x 65 x $30 \mathrm{cms}$, está conformada por un armazón revestido de telas encoladas, siendo la cabeza de barro y las manos de pasta de madera. Con una composición marcadamente piramidal, destaca así mismo el riquísimo estofado, si bien la suciedad le priva del efecto de magnificencia que una adecuada restauración le puede devolver.

Antes de concluir, y para calibrar el éxito alcanzado por este modelo, cabe mencionar la existencia de otra pieza, no atribuible a Cristóbal Ramos, pero sí a algún artista de su entorno. Se trata de otra imagen de la Dolorosa, igualmente conservada en la sacristía de la iglesia parroquial de Soto (fig. 4), cuya principal característica es la fisonomía de la Virgen, representada con rasgos propios de la edad notablemente adulta, casi anciana. Por lo demás, se trata de una imagen de 96 x 55 x $30 \mathrm{cms}$, con cabeza de terracota y manos de madera. Los vestidos han sido realizados con telas encoladas, siendo su policromía de colores lisos y, desde luego, mucho menos rica que la de las obras atribuidas a Ramos. Por el momento, no resulta posible realizar una adscripción más precisa.

Con el presente artículo se ha querido dar a conocer la existencia de algunas obras que pueden atribuirse con soporte documental al escultor sevillano Cristóbal Ramos en un ámbito territorial tan lejano de su taller como es La Rioja. De este modo, se amplía el círculo de irradiación de su producción artística, normalmente reducido a la provincia de Sevilla y sus zonas limítrofes. La burguesía camerana asentada en Andalucía hizo posible la circulación de piezas artísticas que enriqueció los templos de las localidades de origen con imágenes de notable calidad, como sucede en los casos estudiados de Ajamil y Soto en Cameros. Por otra parte, gracias a la documentación consultada puede precisarse la cronología de algunas obras igualmente atribuibles a Cristóbal Ramos que conserva la Santa Escuela de Cristo de Sevilla. 


\section{BIBLIOGRAFÍA}

Cruz Valdovinos, José Manuel/Sánchez Trujillano, Ma Teresa/Roldán Gutiérrez, Pilar (1992): Platería hispanoamericana en La Rioja, catálogo de la exposición (Logroño, Museo de La Rioja, 18 diciembre 1992 - 7 febrero 1993), Logroño 1992: Museo de La Rioja.

Garmendia Arruebarrena, José (1989): “Cádiz, los vascos y la carrera de Indias”. En: Vasconia. Cuadernos de historia - geografia, 13, pp. 11-231.

Labarga, Fermín (2006): Cofradias de Valvanera. Cauce de identidad riojana, Logroño: Instituto de Estudios Riojanos. Labarga, Fermín (2013): La Santa Escuela de Cristo, Madrid: BAC.

Madoz, Pascual (1845): Diccionario geográfico-estadístico-histórico de España y sus provincias de Ultramar, I, Madrid: Est. Literario-Tipográfico de P. Madoz y L. Sagasti.

Martínez Lara, Pedro Manuel/Iván de la Torre Amerighi (2017): "Una escultura desconocida de Cristóbal Ramos (17251799). Iconografía, uso artístico y mentalidad ilustrada a propósito de una imagen de San José con Niño". En: Liño: Revista anual de historia del arte, 23, pp. 57-68.

Montesinos Montesinos, Carmen (1986): El escultor sevillano D. Cristóbal Ramos (1725-1799), Sevilla: Diputación Provincial.

Moreno Arana, José Manuel (2017): “Tres nuevas obras del escultor Cristóbal Ramos". En: Laboratorio de Arte, 29, pp. 819-826.

Moya Valgañón, José Gabriel (1988): "Sobre algunas esculturas cortesanas dieciochescas". En: Brocar: Cuadernos de investigación histórica, 14, pp. 157-169.

Moya Valgañón, José Gabriel (dir.) (2005): Historia del arte en La Rioja, IV: Los siglos XVII y XVIII, Logroño: Fundación Caja Rioja.

Ramírez Martínez, José Manuel (1993): Retablos mayores de La Rioja, Logroño: Obispado de Calahorra y La Calzada - Logroño.

Roda Peña, José (2014): "La escultura barroca del siglo XVIII en Andalucía occidental”. En: Cuadernos de Estepa, 4, pp. 84-111.

Roda Peña, José (2018): “Esculturas de Cristóbal Ramos en la capilla de San José de Sevilla”. En: Laboratorio de Arte: Revista del Departamento de Historia del Arte, 30, pp. 303-318.

Ruiz Rivera, Julián Bautista (1988): El Consulado de Cádiz. Matrícula de comerciantes 1730-1823, Cádiz: Diputación Provincial.

Fecha de recepción: 20-XII-2018

Fecha de aceptación: 17-V-2019 